\title{
High-Throughput Single Nucleotide Polymorphism Genotyping by Fluorescent 5' Exonuclease Assay
}

BioTechniques 27:538-552 (September 1999)

Phillip A. Morin, Robert Saiz
and Atousa Monjazeb

Axys Pharmaceuticals, La Jolla, CA, USA

\section{ABSTRACT}

Single nucleotide polymorphisms (SNPS) are the class of DNA variants that are most common in the genome. Technologies are needed that allow relatively highthroughput, high-quality genotyping of SNPs, with rapid assay development for individual SNPs of interest. We have implemented an accurate and high-throughput SNP genotyping system using a commercially available fluorescent $5^{\prime}$ exonuclease assay. Optimization of the assay system for low-volume reactions and low-probe concentrations has reduced assay costs by $75 \%$. Using a simple assay optimization process, we successfully developed genotyping assays for $92 \%$ of assays attempted (309 out of 335) and have generated over 200000 genotypes.

\section{INTRODUCTION}

Single nucleotide polymorphisms (SNPs) are the next frontier in genomewide polymorphism screening for gene mapping, positional cloning and association studies $(1,5,16)$, and the rush to obtain and screen SNPs has spawned both private and public research into new technology to meet those goals (10-12). These whole-genome screening methods, however, are orders of magnitude beyond the needs of many research programs aimed at identifying and/or screening dozens or hundreds of SNPs in target populations. In addition, these methods might not allow the flexibility to rapidly and inexpensively implement a survey of a novel polymorphism or to screen all of the polymorphisms in a gene region.

For these reasons, technologies are needed that allow relatively highthroughput, high-quality genotyping of SNPs, with rapid assay development, for individual SNPs of interest. Current popular methods include restriction fragment-length polymorphism analysis of polymerase chain reaction products (RFLP-PCR) (with gel electrophoresis for fragment detection), allele-specific oligonucleotide (ASO) hybridization $(3,17,18)$, oligonucleotide ligation assay (OLA) $(2,20)$, "minisequencing" (14) and the $5^{\prime}$-exonuclease assay, or $\mathrm{TaqMan}^{\mathrm{TM}}(4,6,7,9)$. Cost, number of steps, complexity of reactions, precision, accuracy, speed of completion and potential for automation are all important considerations for deciding which system will be used in particular settings, and Syvänen and Landegren (19) reviewed these factors for ASO, OLA and minisequencing in the context of several laboratory settings.

We have evaluated and/or used all of the above methods, and we adopted the $5^{\prime}$ exonuclease assay as our system of choice for high-throughput SNP screening. This assay takes advantage of the $5^{\prime}$ exonuclease activity of Taq DNA polymerase to cause cleavage of allele-specific probes, which are hybridized to template DNA during PCRs. The probes are double-labeled with reporter (FAM or TET) and quencher (TAMRA) dyes at the $5^{\prime}$ and $3^{\prime}$ ends, respectively, and cleavage of the probes causes increase in the fluorescence of the reporter dyes in solution. Differential hybridization of the two allele-specific probes results in cleavage of the probes only if they are perfectly annealed to their respective allele templates, resulting in increase of fluorescence of one or both reporter fluors that can be plotted and segregated to determine the template genotype. The advantages of this assay over ASO and OLA include (i) single-tube amplification and detection, (ii) fluorescence signal proportional to PCR product amplification, (iii) lower reagent and labor costs per genotype, (iv) genotype assignment based on clearly separated clusters of fluorescent values and $(v)$ simple, automatable assay implementation procedures. We used the LS-50B fluorescent spectrometer with a plate reader and the ABI PRISM $^{\circledR} 7700$ Sequence Detector (both from PE Biosystems, Foster City, CA, USA) for data acquisition and analysis (see Discussion).

This manuscript outlines our methods and modifications to the protocols for the $5^{\prime}$ exonuclease assay system, 
current and potential throughput in our laboratory and automation systems for increasing efficiency. These modifications and the supporting data were generated over 3 years of assay development and genotyping, so different experiments were conducted with different assays and sample subsets.

\section{MATERIALS AND METHODS}

\section{Primer and Probe Design}

Oligonucleotide PCR primers and double dye-labeled probes were designed using Primer Express ${ }^{\mathrm{TM}}$ (Version 1 for Macintosh ${ }^{\circledR}$ Power PC; PE Biosystems), and assay design and conditions are primarily based on the allelic discrimination protocol from PE Biosystems (8). Default conditions in the program were used for reaction conditions, and the following parameters were set before selecting primers: primer concentration $=250 \mathrm{nM}$; primer melting temperature $\left(\mathrm{T}_{\mathrm{m}}\right)$ range $=58^{\circ}-60^{\circ} \mathrm{C}$; primer optimal $\mathrm{T}_{\mathrm{m}}=59^{\circ} \mathrm{C}$; maximum primer $\mathrm{T}_{\mathrm{m}}$ difference $=2^{\circ} \mathrm{C}$; probe does not have a $5^{\prime}$ ' $\mathrm{G}$ '; probe $\mathrm{T}_{\mathrm{m}}$ must be $7^{\circ}$ greater than primer $T_{m}$. Other parameters were changed if necessary to allow the program to select primers near the probe. The OLIGO 5.0 program (National Biosciences, Plymouth, MN, USA) has also been used effectively. Using the default conditions, probe sequences were designed to have $\mathrm{T}_{\mathrm{m}} \mathrm{s}$ of $76^{\circ} \mathrm{C}$, and primers were designed for a $\mathrm{T}_{\mathrm{m}}$ of $69^{\circ} \mathrm{C}$. Empirically, optimized annealing temperatures $\left(\mathrm{T}_{\mathrm{a}}\right)$ for assays designed with either program were found to be approximately $60^{\circ}-62^{\circ} \mathrm{C}$ in the PCR conditions outlined below.

Probes were selected in Primer Express to obtain a theoretical $\mathrm{T}_{\mathrm{m}}$ of $67^{\circ} \pm$ $1^{\circ} \mathrm{C}$, with the polymorphic site as close to the center of the oligonucleotide as possible to provide the greatest difference in $T_{m}$ between perfectly matched probe and template and the mismatch. Slight changes in probe length were made to keep the $T_{m}$ constant for the two allele-specific probes (e.g., a probe with an ' $A$ ' might be 1-3 nucleotides [nt] longer than the alternate allele probe containing a ' $G$ ' at the polymorphic site). This design should allow perfectly matched probes to hybridize strongly to the template DNA before the PCR primers anneal and to be cleaved rather than displaced by the Taq DNA polymerase during the extension phase. Mismatched probe/template pairs will be unstable at the PCR cycling conditions, and thus will not be cleaved.

Once probe sequences were selected, all possible PCR primer pairs were determined automatically by Primer Express, and a pair was selected based on the optimal criteria of the program (as indicated by the Penalty score), product length ( $\leq 150 \mathrm{bp})$ and by having the forward primer close $(\leq 30 \mathrm{bp}$ if possible) to the $5^{\prime}$ end of the probe. The distance between the forward primer and the probe (which both anneal to the same strand of the template DNA) is important if they are further than approximately $150 \mathrm{bp}$ apart. We have found that signal intensity often falls off substantially if the forward primer is more than $100 \mathrm{bp}$ from the probe binding site (data not shown). The two alternate allele probes were synthesized with the reporter dyes FAM and TET, respectively, on the $5^{\prime}$ nucleotides, and with TAMRA and a blocking phosphate on the $3^{\prime}$ nucleotide, and then HPLCpurified. Primer oligonucleotides were unmodified and unpurified. For some AT-rich sequences, probe sequences can be over $40 \mathrm{nt}$. Such long probes tend to have higher background fluorescence, but some work well regardless.

All probes were synthesized by $\mathrm{PE}$ Biosystems or Integrated DNA Technologies (IDT; Coralville, IA, USA). PCR primers were synthesized by Operon Technologies (Alameda, CA, USA).

\section{PCR Annealing Temperature Optimization}

A test for PCR product amplification was conducted for each primer pair to determine the optimal amplification temperature. Replicate PCRs were performed on a single DNA sample (20 ng of DNA dried into wells of 96-well PCR plates) at $58^{\circ}, 60^{\circ}$ and $62^{\circ} \mathrm{C}$ using 200 $\mathrm{nM}$ final primer concentration, in $1 \times$ TaqMan PCR Master Mix (PE Biosystems), without assay probes. The PCR products were electrophoresed through $2 \%$ agarose gel in the presence of ethidium bromide and visualized by fluorescence in UV light, and the $\mathrm{T}_{\mathrm{a}}$ that pro- duced the highest product yield was selected for all future amplifications.

\section{Fluorescence Optimization}

Fluorescence signal intensity was optimized by testing an array of primer concentrations [forward:reverse (nM): 300:50, 300:300, 300:900, 900:50, 900:300 and 900:900] using standard assay conditions (below). This subset of concentration pairs for the two primers was derived empirically to reduce the number of reactions that need to be run for each assay optimization. The PCR products, amplified in triplicate (with both probes present) for each set of concentrations, were analyzed in the ABI PRISM 7700 Sequence Detector for the change in the fluorescence of one or both of the reporter dyes relative to the quencher dye $(\Delta \mathrm{RQ})$, and the concentrations that produced the maximum $\Delta \mathrm{RQ}$ were selected for the assay.

\section{Assay Conditions}

Genomic DNA $(5 \mu \mathrm{L}$ of $4 \mathrm{ng} / \mu \mathrm{L}$ DNA in low EDTA TE $[10 \mathrm{mM}$ Tris, $0.1 \mathrm{mM}$ EDTA, pH 8.0]) for each sample was aliquoted into 96-well PCR plates (Robbins Scientific [Sunnyvale, CA, USA] or Corning Costar [Cambridge, MA, USA]) dried at $80^{\circ} \mathrm{C}$ for about $30 \mathrm{~min}$ and stored at ambient conditions until used. PCR cocktails including both probes (100 $\mathrm{nM}$ each) were set up using the derived primer concentrations and 1× TaqMan ${ }^{\mathrm{TM}}$ PCR Master Mix for the 7700, or Buffer II (100 mM Tris, $\mathrm{pH}$ 8.0, $500 \mathrm{mM} \mathrm{KCl,} \%$ gelatin), with $7.5 \mathrm{mM}$ magnesium chloride, the dNTPs (dA, G, C, U; 1:1:1:2 ratio), 0.05 $\mathrm{U} / \mu \mathrm{L}$ AmpliTaq Gold ${ }^{\mathrm{TM}}$ (PE Biosystems) and 0.01 U/ $\mu \mathrm{L}$ Uraci-DNA-Glycosylase for the LS-50B. Five, ten or twenty microliters of the PCR cocktail were added to each well of the 96-well plate, and the plates were sealed with either caps or transparent plastic sealers (Seal-PLT-100; Elkay Products, Shrewsbury, MA, USA). PCR amplification was achieved under the following cycling conditions: $2 \mathrm{~min}$ at $50^{\circ} \mathrm{C}, 10 \mathrm{~min}$ at $95^{\circ} \mathrm{C}$, then 40 cycles of $94^{\circ} \mathrm{C}$ for $30 \mathrm{~s}$, $60^{\circ} \mathrm{C}$ (or empirically derived optimal $\mathrm{T}_{\mathrm{m}}$ ) for $30 \mathrm{~s}$. After cycling, samples remained at $4{ }^{\circ} \mathrm{C}$ until removal from the PCR thermal cyclers for analysis. 


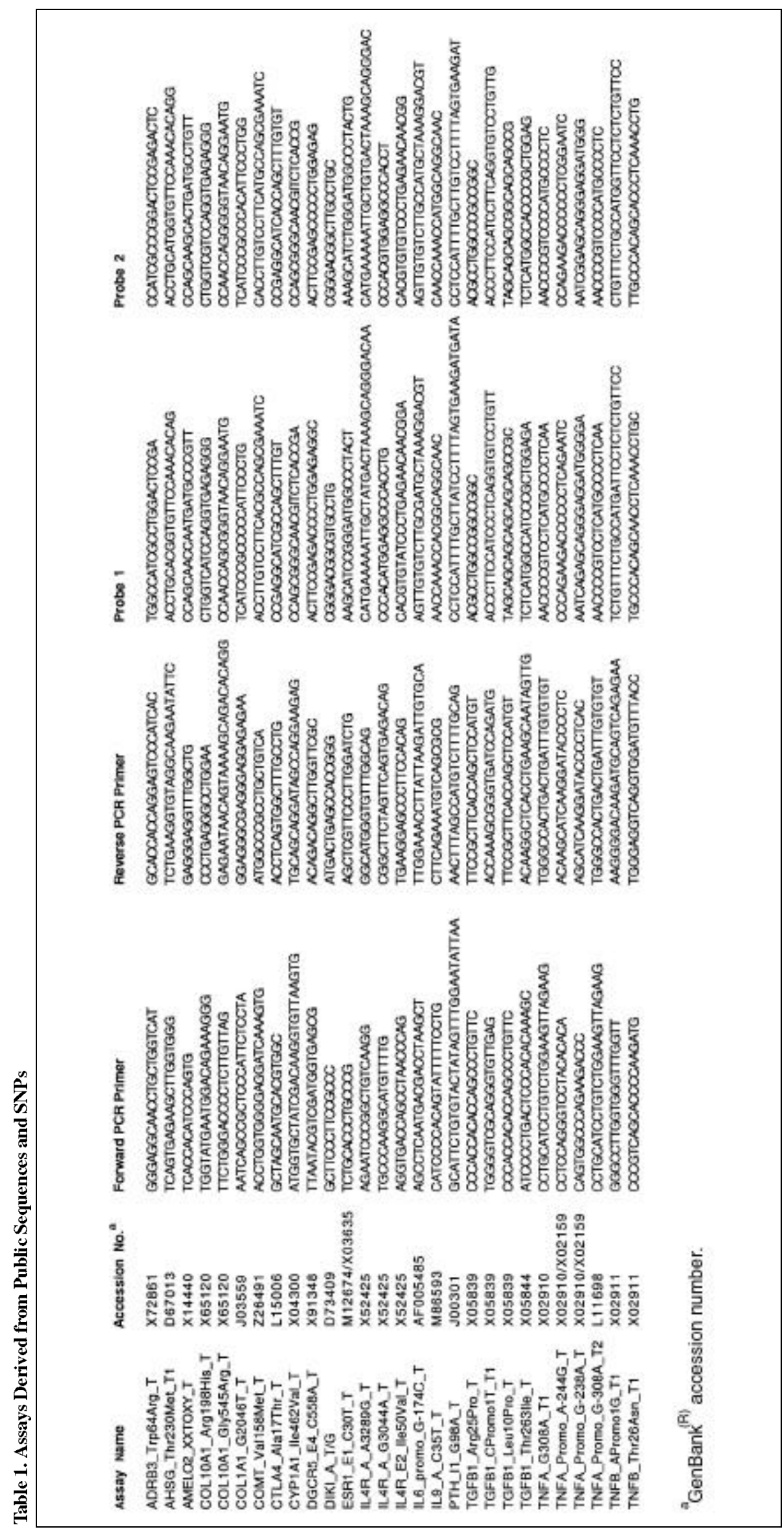

\section{Data Acquisition and Analysis}

Before we acquired the ABI PRISM 7700 Sequence Detector, we used the LS-50B Fluorometer with plate reader for data acquisition and analysis on 256 of the assays summarized in this report. Excel $^{\circledR}$ macros for data analysis were written by Jeff Marmaro (PE Biosystems) (9) and modified by P.A.M. This software uses a set of control genotypes as references to call alleles. The assays were done in $20-\mu \mathrm{L}$ reaction volumes, diluted to $50 \mu \mathrm{L}$ with deionized water and transferred to reflective white plates for fluorescence detection.

For 79 assays, analyzed on the ABI PRISM 7700 Sequence Detector, plates were placed into the sequencer and analyzed for post-PCR allelic discrimination without normalization. The dye component data for each well are displayed graphically and in a table, and alleles can be assigned directly from the graphical display using a selection function in the software and a drag-down menu of genotype options, then exported for spreadsheet or database storage.

\section{RESULTS}

\section{Number of Assays}

To date, we have designed $5^{\prime}$ exonuclease assays for over 330 SNPs, and we typically genotype between 300 and 3000 individuals per assay. We use publicly available polymorphisms (Table 1) and novel SNPs derived from resequencing projects to design new assays following simple rules outlined by PE Biosystems (8).

\section{Assay Conditions}

Maximizing the fluorescence signal created by cleavage of the dual-labeled probes is critical, especially when using the ABI PRISM 7700, as it is less sensitive than the LS-50B Fluorometer and other fluorometers. Optimal temperature and primer concentrations for the PCRs are determined using (i) multiple temperatures to find the highest temperature at which we obtain high PCR product yield (detected by agarose gel electrophoresis), and (ii) primer concentration matrices for PCRs in the 
presence of the fluorescent probes to determine the primer concentrations that result in the greatest fluorescent signal of one or both of the probes from one DNA sample. Assays are designed to use a PCR primer $\mathrm{T}_{\mathrm{a}}$ of approximately $60^{\circ} \mathrm{C}$, and $95 \%$ ( 75 out of 79 ) of assays optimized for the ABI PRISM 7700 have optimal $\mathrm{T}_{\mathrm{a}} \mathrm{s}$ between $58^{\circ}$ and $62^{\circ} \mathrm{C}$. We have tried several primer concentration matrices, and find that $96 \%$ (51 out of 53) of assays have optimal concentrations falling within a $300 \times 900 \mathrm{nM}$ matrix (forward:reverse primer concentration: $300: 300,15 \%$; 300:900, 25\%; 900:300, 17\%; and 900: $900,40 \%$ ). The differences between assays amplified with the empirically derived optimal PCR primer concentrations and alternative concentrations are primarily in the signal intensity of one or the other fluorescent dye, which will tend to skew the heterozygote genotype cluster toward one or the other homozygote cluster.

\section{PCR Cocktail Reagents}

The 7700 ABI PRISM is less sensitive than the LS-50B Fluorometer and uses different software for fluorescent dye spectral analysis, so signal intensity is more important when using the Model 7700. Initial assays were performed using PE Biosystem's Buffer II (see Materials and Methods) with 7.5 $\mathrm{mM}$ magnesium chloride; however, the manufacturer now markets a proprietary $2 \times$ buffer mixture that includes a passive dye (ROX) as an internal standard, produces high signal intensity for most assays and includes the dNTPs, AmpliTaq Gold and Uracil-DNA-Glycosylase in the mixture. Thus, only probes, primers, DNA and water need to be added for each reaction. This is convenient and increases quality control in assay preparation. We have further increased efficiency and consistency among samples by diluting all samples to $4 \mathrm{ng} / \mu \mathrm{L}$, aliquoting $20 \mathrm{ng}$ of DNA into replicate PCR plates using a 96-syringe pipettor (Robbins Scientific) and drying the replicate plates. This allows us to add the PCR cocktail (also using the 96-syringe pipettor) to plates with the DNA already in place, preventing sample mix-up and reducing variation in pipettor volume.

\section{Reaction Volume}

To date, we performed about 200 of our assays in $20-\mu \mathrm{L}$ volumes, instead of $50 \mu \mathrm{L}$ as suggested by PE Biosystems, as initial tests indicated no loss of genotype quantities or quality (data not shown). To quantify the success rate using $20-\mu \mathrm{L}$ reactions, we surveyed all 46 assays genotyped during the 7-month period just before we switched to $10-\mu \mathrm{L}$ reactions. From those assays, there were 53165 genotypes generated from 639 plates, with an overall scorable genotype rate of $93.7 \%$ (standard deviation [SD]: $0.07 \% /$ plate or $\leq 6.6$ genotypes depending on how many samples were on the plate). We have recently shown that $10-$ and $5-\mu \mathrm{L}$ volumes can be used in the same 96-well plates without significant loss of fluorescence or allelic discrimination (Figure 1A). For 40 assays performed with 5- or $10-\mu \mathrm{L}$ volumes, we have achieved a mean of 94.3\% scorable genotypes per 96-well plate (339 plates genotyped). This further indicates that reaction volume down to $5 \mu \mathrm{L}$ does not affect the scorability of the data, but we must caution that in some thermal cyclers, the small volume reactions fail more frequently. The PCRs for these assays have been performed in 96-well plates (from Robbins Scientific or Corning Costar) in a PTC- $100^{\mathrm{TM}}$ Thermal Cycler (MJ Research, Watertown, MA, USA) and with GeneAmp ${ }^{\circledR}$ PCR Systems 9600 and 9700 with thermal lids (both from PE Biosystems). We evaluated the use of mineral oil overlays for small volume $(5 \mu \mathrm{L}) \mathrm{PCR}$, but found that it was not necessary for amplification, and it reduced the fluorescent signal detected by the ABI PRISM 7700 (data not shown).

\section{Signal Strength and Allelic Discrimination}

PCRs were optimized (see Materials and Methods) to produce the maximum signal-to-noise ratio. Probe concentration affects overall signal intensity and, to a much lesser extent, allelic discrimination. The suggested probe concentration is $200 \mathrm{nM}$, but we have found that little resolution is lost by using $100 \mathrm{nM}$ of each probe, and twice as many reactions can be performed (Figure 1B). Where optimal conditions cannot be found using these initial steps, signal strength and allelic discrimination can sometimes be increased by increasing primer concentrations, addition of PCR cycles and/or longer annealing times (e.g., 60 s vs. 30 s) (data not shown).

\section{Assay Reproducibility and Accuracy}

To test the reproducibility of the assays, we selected five assays and genotyped four plates in duplicate using 10$\mu \mathrm{L}$ volumes (on separate days with new PCR cocktail prepared each time). Out of 3760 genotypes total, there was one inconsistent genotype call. Forty-four genotypes $(1.2 \%)$ were called "null" because they either failed to amplify in one replicate or were not given a genotype designation because they were questionable (i.e., fell outside of the expected clusters of points). The overall success rate (percent accurately called genotypes) per assay ranged from $98.1 \%$ to $99.6 \%$. Figure 2 shows a single duplicate set of plates for each assay.

To estimate the accuracy of the assays, we examined the Mendelian inheritance for 26 assays genotyped on a single 10-generational pedigree of 555 individuals from the island of Tristan de Cunha, from which we have sampled 265 individuals who were living on the island in 1997. This pedigree is extremely well studied, so we are confident that there are no incorrect relationships. We found seven genotypes, $(0.1 \%)$ out of 6653 , that were not compatible with Mendelian inheritance in this pedigree.

\section{Failed Assays}

Assay quality is dependent on amplification of the product and appropriate annealing and cleavage of the probes in the PCR. Although primer picking programs help to select primers and probes that have optimal base composition, $\mathrm{T}_{\mathrm{a}} \mathrm{s}$ and lack of secondary structure, they are not perfect, especially given the high magnesium concentrations and other assay reagents that affect the PCR. We have found that in the majority of cases, our assays work with no additional optimization beyond the initial temperature and primer concentration matrices (see Materials and Methods). The most frequent reason for failure is lack of product amplification, which can be over- 


\section{Research Report}

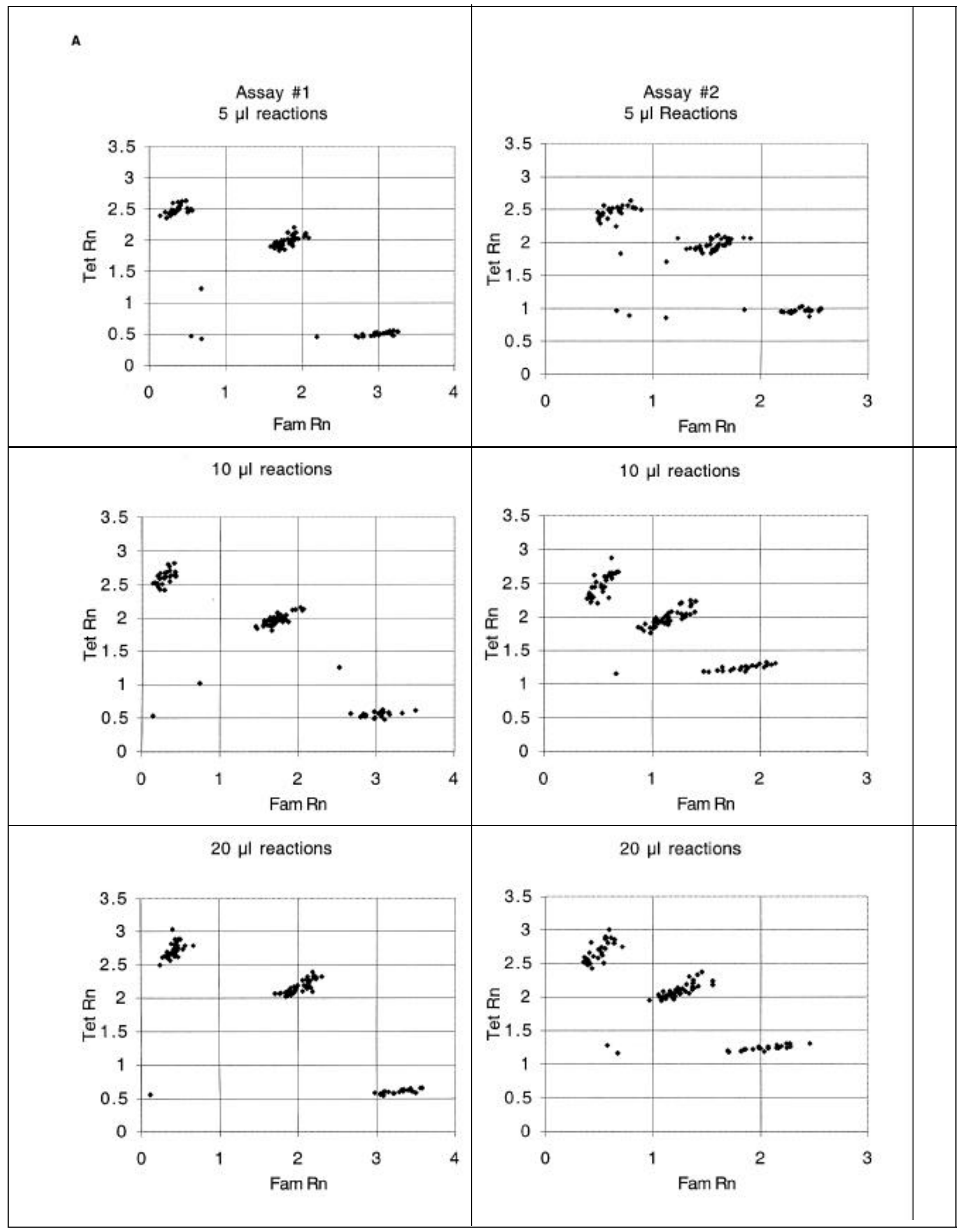


come by additional changes to the PCR conditions (e.g., lower annealing temperature, higher primer concentration, etc.) or by redesigning the PCR primers. In a few cases in which assays have not been resurrected by primer redesign, the most frequent putative cause (3 assays out of 4 analyzed) has been long probe sequences (>40 nt) designed in A/T-rich DNA regions.

\section{B}

\section{Probe concentration: $100 \mathrm{nM}$}

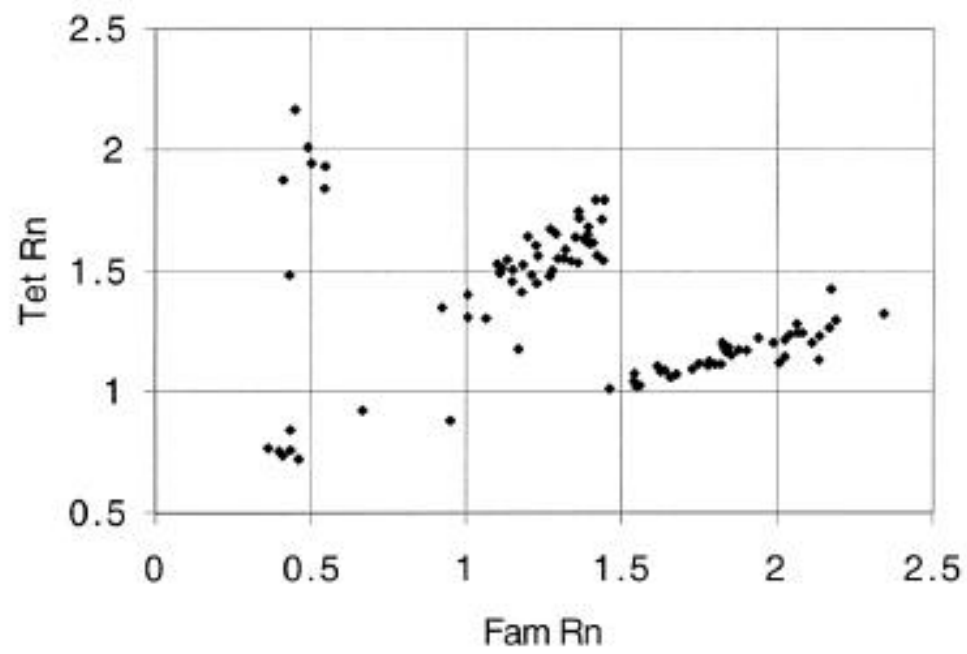

Probe concentration: $200 \mathrm{nM}$

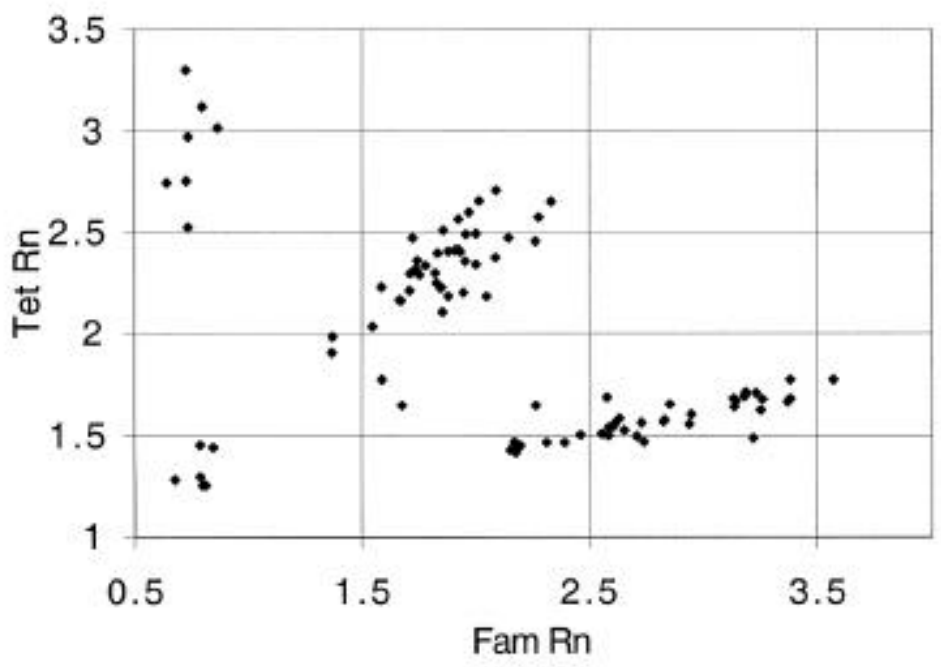

Figure 1. (A) Results from two assays completed on the same 94 DNA samples, using 5-, 10-, and 20- $\mu \mathrm{L}$ PCR volumes. Graph scales have been held constant between different volumes for each assay. The three clusters of points in each graph represent the allele 1 homozygotes (lower right), heterozygotes (middle), allele 2 homozygotes (upper left) and low or no-amplification samples and controls (lower left). Each plate contains one pooled DNA sample, which often falls between the cluster of heterozygote data points and the most common allele data points. (B) Typical results for probe concentrations of 100 and $200 \mathrm{nM}$ (volume $=20 \mu \mathrm{L}$ ). The graph scales have been changed to show that relative distribution of points remains constant even though the overall fluorescent intensity changes with probe concentration.

\section{DISCUSSION}

The data quality of this assay system, along with the 1-tube assay that requires no post-PCR processing, makes the $5^{\prime}$ exonuclease assay very attractive for high-throughput genotyping. ASO hybridization systems with high-density arrays can produce higher throughput; however, signal and background variation among samples and assays have caused a higher rate of genotype ambiguity and miscalls for us in the past. Our system of checking for Mendelian inheritance problems in extended pedigrees has shown that we rarely have any incorrect genotypes from $5^{\prime}$ exonuclease assays.

We have addressed two of the primary limitations of this system: $(i)$ the high cost of reagents and (ii) the ability to automate PCR setup and amplification through reduction of reaction volumes. We have designed over 340 systems for the $5^{\prime}$ exonuclease assay and completed genotyping of 300-3000 DNA samples for most of them (>200000 genotypes). To date, using the methods described here, over $95 \%$ of the assays have been optimized, and they produced highquality genotype data, most of which has been verified by checks for Mendelian inheritance in extended pedigrees. Our primary modifications of PE Biosystems protocols for these assays have included drying DNA into plates, PCR product optimization and an abbreviated primer concentration optimization step, and reduced volume PCRs. Our optimization procedure requires 33 PCRs (when done in triplicate) and nine agarose gel lanes per assay. This is a reduction of 33 PCRs and gel lanes from the optimization protocol recommended by PE Biosystems for allelic discrimination (15), which requires 64 PCRs (but does not suggest checking products on agarose gels).

The cost per reaction is approximately $\$ 0.42$ for the $10-\mu \mathrm{L}$ reaction volume (including all consumable materials), assuming full use of the probes (about 10000 reactions). The $2 \times$ PCR mixture from PE Biosystems costs $\$ 0.34 /$ reaction, and the probe costs vary by manufacturer, but can generally be purchased for about $\$ 400$ each or $\$ 800$ for an assay with enough probe to perform at least $1000010-\mu \mathrm{L}$ reactions. 


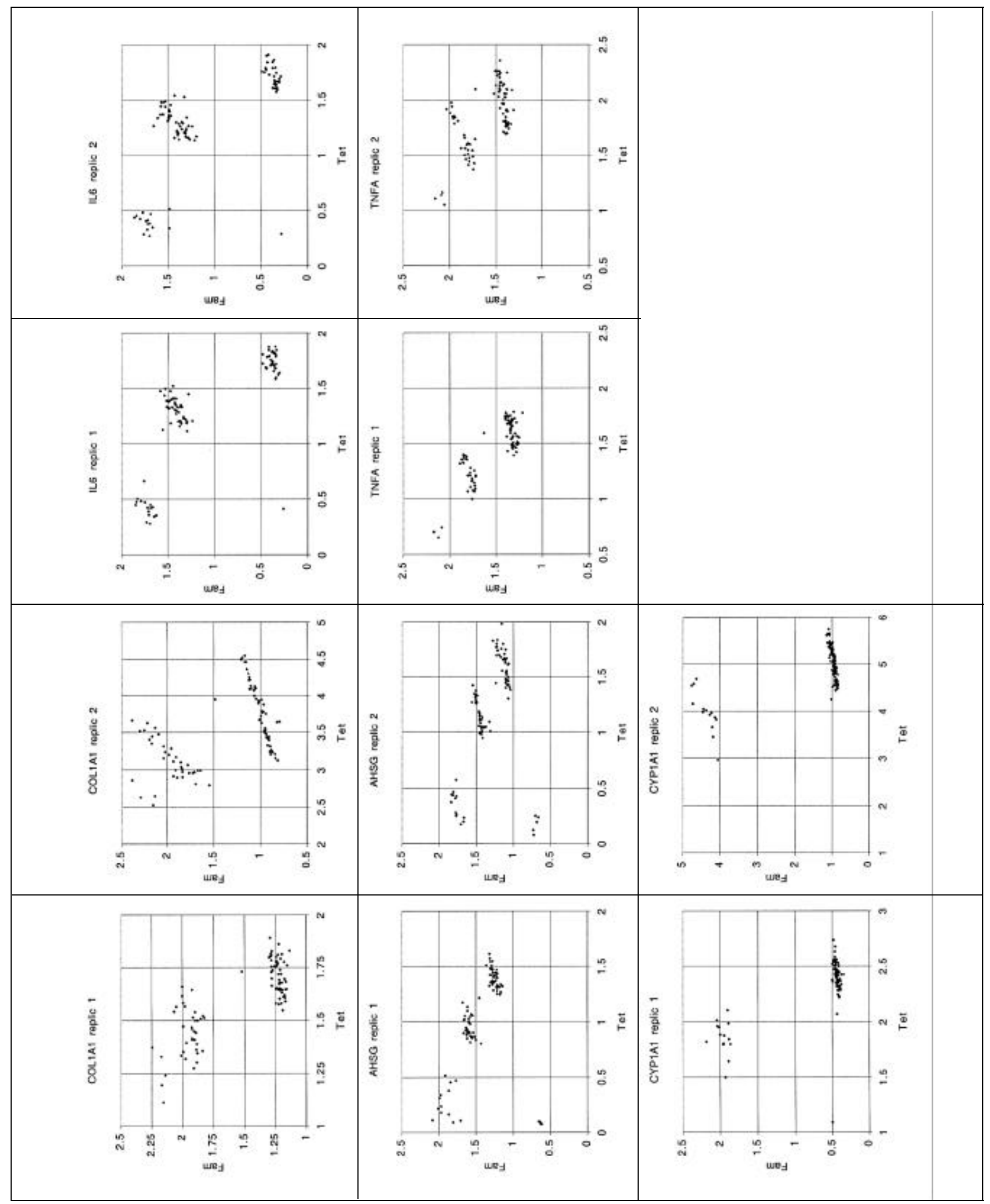

Figure 2. Results from five assays completed in duplicate, $10-\mu \mathrm{L}$ reaction volumes. Five 96 -well plates were genotyped in duplicate for each assay for estimates of reproducibility, and one representative set of duplicate plates is shown for each assay. The Cyp1A1 SNP assay detected no homozygotes for the rare allele for the plate shown here. The two clusters are for the common homozygotes and the more rare heterozyotes. 
These costs can be decreased by using a homemade buffer mixture instead of the $2 \times$ Master Mix (PE Biosystems) or by developing even smaller volume PCR amplification and fluorescence detection methods.

The primary bottlenecks in this production line are primer and probe synthesis (typically 3 days for primers, 5-7 days for probes), optimization steps and availability of thermal cyclers needed to amplify 5000-10000 samples.

The time needed for primer and probe synthesis has been decreased by changes in probe synthesis techniques that have eliminated post-synthesis HPLC purification, addition of TAMRA to each probe and a second HPLC purification (13).

Optimization steps have been implemented to maximize the chances that an assay will work reliably when applied across hundreds or thousands of samples. The possible permutations in each optimization, however, have been gradually reduced after optimization of dozens of assays to minimize the reagents, labor and time involved. We originally tested five annealing temperatures for each assay $\left(56^{\circ}, 58^{\circ}, 60^{\circ}, 62^{\circ}\right.$ and $64^{\circ} \mathrm{C}$ ), a matrix of nine probe concentrations (100, 500 and $900 \mathrm{nM})$, and a matrix of nine primer concentrations (50, 300 and $900 \mathrm{nM}$ ) for assay optimization. We have empirically derived a subset of optimization steps and dropped the probe concentration matrix altogether, for a smaller set of steps which yields robust results for $95 \%$ of our assays (see Materials and Methods).

Volume reduction presents several cost-saving and labor-saving benefits. First, the PCR components $(2 \times$ Master Mix), including enzymes and passive dye standard (ROX), which make up approximately $80 \%$ of the disposable materials costs (excluding probes) with 20 $\mu \mathrm{L}$ reactions, are reduced to $66 \%$ of disposable materials costs with $10-\mu \mathrm{L}$ reactions. Second, probe synthesis is a fixed cost that is about $\$ 0.16 /$ reaction when $\leq 5000$ genotypes are processed at the $20-\mu \mathrm{L}$ volume, but reducing volume to $10 \mu \mathrm{L}$ obviously allows double the number of genotypes for the same cost - a $50 \%$ reduction in the per genotype cost. Third, mixing and aliquoting of smaller volumes is more easily automated for robotic workstations, thereby reducing labor and potential for human error. Finally, small volumes can be cycled more efficiently in the thermal cyclers, so more plates can be cycled through each machine in a day, and automatic transfer of plates into and out of a PCR thermal cycler is ultimately achievable for amplifying large numbers of plates without the need for a person to feed the plates into multiple PCR machines.

Hardware and software for analysis of $5^{\prime}$ exonuclease assay results are currently available with the ABI PRISM 
7700 Sequence Detector. This system provides software for rapid analysis of the data. An alternative to this specialized and expensive instruments is a simple fluorometer with the ability to detect multiple fluorescent emission wavelengths in the 500-600-nm range. Excel macros, developed by $\mathrm{PE}$ Biosystems (9) and modified by us, can be used to organize the fluorescent emission data, to separate alleles based on controls by multicomponent analysis of the wavelengths and to automate genotype calls. This system (using the LS-50B Fluorometer with plate reader) has worked well for us; however, it requires transfer of samples from PCR plates to reading plates, assumptions and cut-offs for allele calling and manual checking of genotypes to be sure that the allele calling was accurate. As most fluorometers are more sensitive than the ABI PRISM instruments, assays developed for fluorometers do not need to be optimized as much as the assays we have described here. The benefit of the fluorometer-based system is that it can make use of equipment and software presently available in many laboratories, but at the expense of precise and user-friendly hardware and software that allow high throughput in analysis and quality control.

The $5^{\prime}$ exonuclease assay system incorporates (i) ease of assay design, (ii) commercial availability of oligonucleotide probes, instruments and analysis software and (iii) scalability for laboratories producing $<100$ genotypes to those producing ten-thousand genotypes per week. Although this system is unlikely to meet the needs of genome-wide SNP screening as proposed by several authors $(1,5,15)$, for population-level genotyping of specific polymorphisms, candidate genes and disease genes, this system offers ease of use, throughput and accuracy not previously available.

\section{ACKNOWLEDGMENTS}

We thank Shelley Webster at Axys and Gianfranco DeFeo and Chris Grimley of PE Biosystems for technical help. We also thank Chris Hinckel for discussion and advice and Andy Watson, Penny Isabella and several anonymous reviewers for useful suggestions.

\section{REFERENCES}

1.Collins, F.S., M.S. Guyer and A. Chakravarti. 1997. Variations on a theme: cataloging human DNA sequence variation. Science 278:1580-1581.

2.Delahunty, C., W. Ankener, Q. Deng, J. Eng and D.A. Nickerson. 1996. Testing the feasibility of DNA typing for human identification by PCR and an oligonucleotide ligation assay. Am. J. Hum. Genet. 58:1239-1246.

3.Handelin, B. and A.P. Shuber. 1996. Simultaneous detection of multiple point mutations using allele-specific oligonucleotides, $p$. 9.4.1-9.4.5. In N.C. Dracopoli, J.L. Haines, B.R. Korf, D.T. Moir, C.C. Morton, C.E. Seidman, J.G. Seidman and D.R. Smith (Eds.), Current Protocols in Human Genetics. John Wiley \& Sons, New York.

4.Holland, P.M., R.D. Abramson, R. Watson and D.H. Gelfand. 1991. Detection of specific polymerase chain reaction product by utilizing the $5^{\prime}$ to $3^{\prime}$ exonuclease activity of Thermus aquaticus DNA polymerase. Proc. Natl. Acad. Sci. USA 88:7276-7280.

5.Lander, E.S. 1996. The new genomics: global views of biology. Science 274:536-539.
6.Lee, L.G., C.R. Connell and W. Bloch. 1993 Allelic discrimination by nick-translation PCR with fluorogenic probes. Nucleic Acids Res. 21:3761-3766.

7.Livak, K., S.J.A. Flood, J. Marmaro, W. Giusti and K. Deetz. 1995. Oligonucleotides with fluorescent dyes at opposite ends provide a quenched probe system useful for detecting PCR product and nucleic acid hybridization. PCR Methods Appl. 4:357-362.

8.Livak, K., J. Marmaro and S. Flood. 1995. Guidelines for designing TaqMan ${ }^{\mathrm{TM}}$ fluorogenic probes for $5^{\prime}$ nuclease assay. PE Applied Biosystems, Foster City, CA.

9.Livak, K.J., J. Marmaro and J.A. Todd. 1995. Towards fully automated genome-wide polymorphism screening. Nat. Genet. 9:341342 .

10.Marshall, E. 1997. 'Playing chicken' over gene markers. Science 278:2046-2048.

11.Marshall, E. 1997. Snipping away at genome patenting. Science 277:1752-1753.

12.Marshall, E. 1997. The hunting of the SNP. Science 278:2047.

13.Mullah, B., K. Livak, A. Andrus and P. Kenney. 1998. Efficient synthesis of double dye-labeled oligodeoxyribonucleotide probes and their application in a real time PCR assay. Nucleic Acids Res. 26:1026-1031.

14.Pastinen, T., A. Kurg, A. Metspalu, L. Peltonen and A.-C. Syvänen. 1997. Minisequencing: a specific tool for DNA analysis and diagnostics on oligonucleotide arrays. Genome Res. 7:606-614.

15.PE Biosystems. TaqMan ${ }^{\circledR}$ Allelic Discrimination Demonstration Kit Protocol. Part No. 4303267. Foster City, CA.

16.Risch, N. and K. Merikangas. 1996. The future of genetic studies of complex human diseases. Science 273:1516-1517.

17.Shuber, A.P., L.A. Michalowsky, G.S. Nass, J. Skoletsky, L.M. Hire, S.K. Kotsopoulos, M.F. Phipps, D.M. Barberio and K.W. Klinger. 1997. High throughput parallel analysis of hundreds of patient samples for more than 100 mutations in multiple disease genes. Hum. Mol. Genet. 6:337-347.

18.Shuber, A.P., J. Skoletsky, R. Stern and B.L. Handelin. 1993. Efficient 12-mutation testing in the CFTR gene: a general model for complex mutation analysis. Hum. Mol. Genet. 2:153-158.

19.Syvänen, A.-C. and U. Landegren. 1994. Detection of point mutations by solid-phase methods. Hum. Mutat. 3:172-179.

20.Tobe, V.O., S.L. Taylor and D.A. Nickerson. 1996. Single-well genotyping of diallelic sequence variations by a two-color ELISAbased oligonucleotide ligation assay. Nucleic Acids Res. 24:3728-3732.

Received 24 March 1999; accepted 21 May 1999.

\section{Address correspondence to:}

Dr. Phillip A. Morin

Axys Pharmaceuticals, Inc.

11099 North Torrey Pines Road, Suite 160

La Jolla, CA 92037, USA

Internet:morin@axyspharm.com 